\title{
Analysis of the Economic Impact of the US Presidential Candidates on the United States and China
}

\author{
Pengzhi Yin ${ }^{1 *}$, Jiasi Peng ${ }^{2}$ \\ ${ }^{1}$ Central South University, Changsha 410083, Hunan province, China. E-mail: 1689701748@qq.com \\ ${ }^{2}$ Affiliated School of Hunan First Normal University, Changsha 410083, Hunan province, China.
}

\begin{abstract}
The presidential election of art and industry: the contest between Trump and Biden has been staged. They have different tax, minimum wage, energy, technology, trade and other strategies, which will inevitably have an impact on the economy of the United States and China. Our team chose this mathematician modeling project to scientifically evaluate the impact of the new president of the United States on the economy of the two countries, and put forward our coping strategies.
\end{abstract}

Keywords: US Presidential Election; Economic Impact; Mathematical Modeling; International Relation

\section{Introduction}

\subsection{Background}

The US presidential election has been recently held in 2020, with Republican candidate Donald Trump and Democratic counterpart Joe Biden running for president. Most economists believe that the uncertainty of the upcoming US presidential election is weakening economic activity. How does the US election affect the economy? Although each election brings some uncertainty to the economy, more than $80 \%$ of the respondents in a recent survey of economists believe that the current election cycle has brought unusual chaos to the economy. $57 \%$ of respondents said the economy was at least partly dragged down by the general election.

No matter who is in the lead, the election period will depress the stock market and the US dollar, while gold and silver will be on the contrary. How does the US election affect the economy? Because the uncertainty of the election is not conducive to the U.S. economy, gold and silver prices may jump after the election, until the candidate takes office and begins to implement his policies.

\subsection{Key points of the problem}

The candidates of both parties have different political stands and administrative programs in finance and trade, economic and financial governance, and some other different key development areas. By way of illustration, COVID-19 fighting measures, infrastructure, taxation, environmental protection, medical insurance, employment, trade, immigration, education. The election of different candidates will shape different strategic patterns of global economic and financial development, and have a greater impact on the U.S. economy and the global economy, which includes China's economy ${ }^{[1]}$.

\footnotetext{
Copyright (C) 2021 Pengzhi Yin et al.

doi: $10.18686 /$ fm.v6i1.3062

This is an open-access article distributed under the terms of the Creative Commons Attribution Non-Commercial License

(http://creativecommons.org/licenses/by-nc/4.0/), which permits unrestricted non-commercial use, distribution, and reproduction in any medium, provided the original work is properly cited.
} 


\subsection{Our work}

First of all, we will analyze a sea of multiple factors. For example, financial and trade, epidemic prevention and control, infrastructure, taxation, environmental protection, immigration, etc., which are analyzed by cluster analysis. Then select the appropriate analysis means and give them the corresponding weight. Next, we establish the appropriate relationship, analyze the ratio of economic change, to determine the impact of the two leaders, and get our scientific response strategy. Last we will give our comprehensive conclusion and scientific analysis.

\section{Factor selection and treatment}

\subsection{Analysis and summary of different policies}

Economic policy: Biden, the "defender of the middle class", advocates increasing the income tax on the rich and enterprises to narrow the gap between the rich and the poor. He claims that "economic security is national security". In terms of employment, he puts more emphasis on raising the minimum wage and promoting racial equality. At the same time, the government should increase economic intervention and strengthen the supervision of the financial market. Biden put forward a four-year $\$ 2$ trillion "climate and infrastructure plan" in his policy proposal to spend on infrastructure, clean energy and expanding health care. The fiscal expenditure will face greater upward pressure. It can be seen that Biden's stimulus policy is not as strong as Trump's in the short term.

Trade policy: Biden supports multilateral free trade, opposes taxation and pays attention to "unfair competition". Biden believes that the United States can benefit more from the existing trade mechanism than unilateralism. Biden has said that once elected, he will stop the punitive tariffs on China, but he still supports the return of American manufacturing industry and strives to maintain the hegemony of the United States in the field of science and technology. Trump: trade protectionism, adhere to the imposition of punitive tariffs on countries carrying out "unfair dumping and subsidies", replace multilateral trade with bilateral trade, and withdraw from TPP. Trump: attracting manufacturing industry to return to the United States, creating jobs, and comprehensively reducing taxes. It emphasizes the driving effect of economic growth on employment and income growth.

Social policy: Biden: safeguard the equality of rights of ethnic minorities; relax immigration restrictions; increase investment in clean energy reform; gradually promote universal health care system; plan to develop a 5G network led by the private sector with US allies; strengthen supervision in the financial sector. Trump: support everyone in the United States to benefit from economic growth; oppose illegal immigration and repatriate illegal immigrants; vigorously develop fossil energy; consider adding 1 trillion US dollars of infrastructure to stimulate the economy, plan to cover roads, bridges, some 5G construction and rural network construction in the United States; oppose universal health insurance, advocate reducing the cost of medical insurance through market competition, and abolish medical insurance in Malaysia will cut the expenses of medic-care and medic-aid, relax financial supervision and pay attention to the rise of stock market.

\subsection{Basis for selecting factors}

First, in terms of the general tone of tax policy, Biden emphasizes tax increase, which is used for health care and infrastructure construction; while Trump continues the tax reduction and Employment Act of 2017.

Secondly, in terms of energy policy, Biden emphasizes the development of new energy and clean energy, while Trump hopes to develop traditional energy and emphasizes energy independence.

Third, in terms of infrastructure, Biden emphasizes the expansion of infrastructure, especially infrastructure related to green economy, while Trump emphasizes the expansion of infrastructure, especially the infrastructure related to $5 \mathrm{G}$.

Fourthly, in terms of regulatory policies, Biden's attitude in the financial sector is not clear, with evidence from hawks and doves; while Trump supports financial deregulation; in the field of science and technology, both support antitrust investigation and platform content review.

Fifth, in terms of trade policy, Biden opposes trade protectionism, while Trump's keynote is that the United States 
gives priority to trade protection.

Sixth, on the minimum wage, Biden supports raising the minimum wage, while Trump is likely to oppose it.

Seventh, in terms of health care policy, Biden supports the price limit of prescription drugs, the expansion of medical insurance expenditure, and the support of Obamacare, while Trump supports the price limit of prescription drugs, reduces medical insurance expenditure and opposes Obamacare ${ }^{[2]}$.

\section{Calculations and building models}

\subsection{Tax policy}

Note: define the boundary utility function $\mathrm{U}, \mathrm{L}$ is the working hours, $\mathrm{L}_{0}$ is the total available hours, $\mathrm{Y}$ is the net household income, $\omega$ is the after tax wage rate, assuming that the indifference curve tends to the origin. Let the extreme value of the boundary utility function be $\varepsilon_{1}$, which is defined as the tax coefficient.

$\mathrm{U}(\mathrm{Y}, \mathrm{L})=\mathrm{u}_{1}(\mathrm{Y})+\mathrm{u}_{2}\left(\mathrm{~L}_{0}-\mathrm{L}\right)$

Maixmize: $x(L) \equiv u_{1}(\omega L+M)+u_{2}\left(L_{0}-L\right)$

$\mathrm{dx}=\omega \mathrm{du}_{1}(\mathrm{Y})-\mathrm{du}_{2}=0$

Derivative $\omega:\left(\omega^{2} \mathrm{u}_{1}{ }^{\prime \prime}+\mathrm{u}_{2}{ }^{\prime \prime}\right) \frac{\partial \mathrm{L}}{\partial \omega}=-\mathrm{u}_{1}^{\prime}-\omega \mathrm{Lu}_{1}{ }^{\prime \prime}$

Derivative $\omega$ again: $\mathrm{u}_{1}^{\prime}+\omega \mathrm{u}_{1}^{\prime \prime} \frac{\partial \mathrm{y}}{\partial \omega}+\mathrm{u}_{2}^{\prime \prime \prime} \frac{\partial \mathrm{L}}{\partial \omega}=0$

$\left(\omega^{2} u_{1}^{\prime \prime}+u_{2}^{\prime \prime}\right) \frac{\partial L}{\partial \omega}=-u_{1}^{\prime}-\omega L u_{1}^{\prime \prime}$

$\left(\omega u_{1}^{\prime \prime} \mathrm{L}+\frac{\mathrm{u}_{2}^{\prime \prime} \mathrm{L}}{\omega}\right) \frac{\omega}{\mathrm{L}} \frac{\partial \mathrm{L}}{\partial \omega}=-\mathrm{u}_{1}^{\prime}\left[1-\left(\frac{\omega \mathrm{L}}{\mathrm{Y}}\right)\left(\frac{-\mathrm{u}_{1}^{\prime \prime} \mathrm{Y}}{\mathrm{u}_{1}^{\prime}}\right)\right]$

The second order condition guarantees that the expression in the bracket on the right side of the equation is negative.

Define: $\frac{-\mathrm{u}_{1}^{\prime \prime} \mathrm{Y}}{\mathrm{u}_{1}^{\prime}} \equiv \varepsilon_{1}$

\subsection{Energy import policy}

Based on Nerlove formula: Note: $\mathrm{Y}$ is defined as output, $\mathrm{X}$ as output factor, $\mathrm{A}$ as Cobb-Douglas factor, $\mathrm{K}$ as capital, $\mathrm{L}$ as labor force and $\mathrm{E}$ as fuel input. According to the properties of the model, $\alpha_{i}, \beta, \gamma_{\mathrm{i}}$ are the partial elasticity coefficients of output to capital, labor and energy respectively.

$\mathrm{Y}=\mathrm{f}\left(\mathrm{x}_{1}, \mathrm{x}_{2}, \ldots \ldots, \mathrm{x}_{\mathrm{k}}\right)$

Using bivariate to produce function model:

$\mathrm{Y}=\mathrm{AK} \mathrm{K}^{\alpha} \mathrm{L}^{\beta}$

Considering the influence of technological progress and market factors on time series data: $\mathrm{Y}=\mathrm{AK}^{\alpha_{1}} \mathrm{~L}^{\beta_{1}} \mathrm{E}^{\gamma}$

Output and sort out the corresponding change of $Y$ :

$\mathrm{dY}_{\mathrm{it}}=\mathrm{Y}_{\mathrm{it}}\left[\frac{\alpha_{\mathrm{i}}}{\mathrm{K}_{\mathrm{it}}} \frac{\partial \mathrm{K}_{\mathrm{it}}}{\partial \mathrm{E}_{\mathrm{it}}}+\frac{\beta_{\mathrm{i}}}{\mathrm{L}_{\mathrm{it}}} \frac{\partial \mathrm{L}_{\mathrm{it}}}{\partial \mathrm{E}_{\mathrm{it}}}+\frac{\gamma_{\mathrm{i}}}{\mathrm{E}_{\mathrm{it}}}\right] \mathrm{dE}_{\mathrm{it}}$

Considering capital, labor and energy respectively:

$\alpha_{i}=\frac{\partial Y_{i t} / \partial \mathrm{K}_{i t}}{Y_{i t} / K_{i t}} \beta_{i}=\frac{\partial Y_{i t} / \partial L_{i t}}{Y_{i t} / L_{i t}} \gamma_{i}=\frac{\partial Y_{i t} / \partial E_{i t}}{Y_{i t} / E_{i t}}$

Sort out the above relations:

$\frac{d Y_{i t}}{d E_{i t}}=3 \gamma_{i} \frac{Y_{\text {it }}}{E_{\text {it }}}$

\subsection{Trade policy}

Note: Combined with the data, we estimate the impact of trade policy on the economy by using the univariate 
high-order polynomial fitting model. Trade volume is represented by $\mathrm{y}$, and economic development index is represented by $\mathrm{x} . \mathrm{r}$ is the fitting coefficient.

First temptation:

$y=-2 \times 10^{7} x^{4}+5 \times 10^{7} x^{3}-4 \times 10^{7} x^{2}+2 \times 10^{7} x-3 \times 10^{6}$

$r_{3}=0.1071639$

Second temptation:

$y=-747560 x^{3}+4 \times 10^{6} x^{2}-6 \times 10^{6} x+3 \times 10^{6}$

$r_{3}=0.0011232$

Third temptation:

$y=3904.6 x^{4}-10^{7} x^{3}+2 \times 10^{10} x^{2}-9 \times 10^{12} x+2 \times 10^{15}$

$r_{3}=0.0004746$

So we can conclude that:

$r_{1}>r_{2}>r_{3}$

Define:

$y=3904.6 x^{4}-10^{7} x^{3}+2 \times 10^{10} x^{2}-9 \times 10^{12} x+2 \times 10^{15}$

\subsection{Minimum wage policy}

Note: Gini index (Gini index, Gini coefficient) is a commonly used international indicator to measure the income gap of residents in a country or region. The maximum Gini coefficient is " 1 ", and the minimum is equal to " 0 ". The closer the Gini coefficient is to 0 , the more equal the income distribution is. According to international practice, below 0.2 is regarded as absolute average income, 0.2-0.3 as comparative average income; 0.3-0.4 as relatively reasonable income; 0.4-0.5 as large income gap; when Gini coefficient is above 0.5, it means income disparity. We define this coefficient as minimum wage control coefficient " $\delta$ ".

Gini $=\frac{\langle\mathrm{M}\rangle-\langle\mathrm{m}\rangle}{\langle\mathrm{M}\rangle+\langle\mathrm{m}\rangle}=\frac{\left\langle\left|\mathrm{x}_{1}-\mathrm{x}_{2}\right|\right\rangle}{2 \mu}$

If the proportion of the total income of the population from group 1 to group $i$ is $\omega_{i}$, then the Lorentz curve passes through the point $\left(\frac{1}{\mathrm{~N}}, \omega_{\mathrm{i}}\right)$. If $\omega_{0}=0, \omega_{\mathrm{n}}=1$, then $\mathrm{I}=0,1,2, \ldots, \mathrm{N}$ on the Lorentz curve are obtained. So we can use trapezoid rule to integrate Lorentz curve to get area $\mathrm{B}$. and $\mathrm{a}+\mathrm{B}=1 / 2$ is the area of right triangle. Finally, Gini coefficient $=\frac{A}{(A+B)}=1-2 B$. Increasing the number of groups $n$ or using Simpson integral method can make the calculation result more accurate.

Refer to $\mathrm{U}(\mathrm{Y}, \mathrm{L})=\mathrm{u}_{1}(\mathrm{Y})+\mathrm{u}_{2}\left(\mathrm{~L}_{0}-\mathrm{L}\right)$ and Gini coefficient

\section{Our conclusion}

\subsection{Who can improve the economy better}

Among the battles mentioned in Biden's victory speeches, "fight for epidemic control" ranked first. It also mentioned that the work will start from the control of the epidemic situation, and a group of top scientists and experts will be appointed as the consultants of the transitional government, and the "Biden Harris new crown containment plan" based on science will be implemented from the inauguration day. This means that the U.S. epidemic prevention policy will be more strict and systematic after Biden takes office, which is expected to ease the current economic and social dis-order caused by the epidemic and stabilize the confidence of economic recovery.

In addition, the relatively clear election results will also help Biden and the two houses of congress to open a new round of fiscal stimulus negotiations as soon as possible, so as to speed up its introduction. However, in terms of strength, considering that the possibility of splitting congress is still large, the final fiscal stimulus plan may have a considerable degree of compromise in non anti epidemic areas, and the total scale is lower than the current Biden and House of Representatives plans ${ }^{[3]}$.

This year's epidemic and the election have exposed the tearing reality of social polarization in the United States, 
which has also attracted wide attention to people's livelihood policies such as taxes and health care after Biden's administration. From the perspective of Biden's policy, improving the distribution structure and bridging social contradictions will gently change Trump's conservative policy tendency. For example, Biden proposed to restore the top rate of personal income tax from $37 \%$ to $39.6 \%$, impose social security tax and long-term capital gains tax on wealthy people and families, and increase corporate tax from $21 \%$ to $28 \%$. It is estimated that $75 \%$ of the households with the top $1 \%$ of income will bear $75 \%$ of the $\$ 4$ trillion tax increase in the next decade. In a nutshell, we suppose Biden has the better ability in dealing with American economy.

\subsection{What is the impact on China's economy}

Comprehensively analyze the possible impact of different candidates elected on China's economy. Biden will unite with allies to curb China's economic development. As we all know, U.S. president Trump is seeking re-election, but in response, Yahoo quoted some economists on Monday as saying that if Trump is re-elected as president of the United States, his position may be much tougher when negotiating with China, which will bring risks to the market and economy. For example, Neil Dutta, head of economics at Renaissance macroeconomics, told a Yahoo finance show that there is a real risk to president Trump's re-election because he does not have the next election threat (the US president can only be re-elected once $)^{[4]}$.

In other words, after his re-election, the Trump administration will be much freer to adopt a much tougher attitude to solve the trade problems with China. In addition, under such circumstances, Trump does not have to worry that such a strategy will stir up stock market volatility or damage the company's supply chain and operation in the short term, thus endangering his presidency.

Wang Ye said that finance and economics have reported many times before that Trump has always regarded himself as a "tariff man". If Trump is re-elected, he is likely to impose more tariff threats on China in 2021.

In response, Duta said: "I think 2020 is just the calm before the storm, and there are real risks before and after the election." use $\tau$ to describe the impact of policy on China's economy, define recent situation as $\tau_{N o w}$.

$\tau_{\text {Now }}=\tau_{\text {Trump }}=0.6667 \times 2400+0.3333 \times 1000=1933.38$

$\tau_{\text {Biden }}=0.6667 \times 2700+0.3333 \times 1100=2166.72$

$\tau_{\text {Biden }}>\tau_{\text {Trump }}$

Just as the US think tank recruited Biden to restrict the attack on China as soon as possible. U.S. think tank expert Freeman pointed out that Sino-US relations are the most important relations in the current period, but the two countries have now changed from ideological confrontation to all-round fundamental opposition in politics, economy, military, culture and other aspects. Therefore, the United States needs to take measures to restrict China as soon as possible. The United States intends to extend its soft power to China. Cultural soft power and other "soft knives" can achieve far-reaching and subtle victories than the hot war without consuming a single soldier. Therefore, American think tanks will certainly continue to promote this model to restrict China after Biden takes office. Whether Biden or Trump is in power, the U.S. national strategy to attack China will not change.

Conclusion: Biden's restrictions on China will be more stringent, because it is determined by national interests. The stronger China is, the more serious such external sanctions will be. However, we should not be restrained and timid. We should vigorously develop science and technology to improve the quality and development level of China's economy.

\subsection{What should we do}

Suggestions we make to China's economic countermeasures and policies in related areas in both cases.

If Trump wins:

First, we should strengthen support for the transformation and upgrading of consumption, improve the consumption and service quality of medium and high-end products, cooperate with the new round of supply side reform of the service industry, focus on solving the problem of mismatch between supply and demand in the consumer sector, and 
increase domestic demand to weaken external shocks.

Second, maintain a positive attitude of opening up, especially in high-tech and service industries, and actively respond through soft diplomacy. In my opinion, if the trade war is inevitable, to some extent, opening up the market seems to be a positive attitude. Although the United States has a high deficit in goods trade with China, its service trade has always been in surplus ${ }^{[5]}$.

Third, adjust the exchange rate policy. At present, the popular view in the market is to increase the flexibility of the exchange rate, release the pressure of devaluation, and let the RMB freely depreciate in place. Although under normal circumstances, the author strongly supports the practice of increasing exchange rate flexibility, but the current monetary policy needs more consideration, that is, under the background of Trump's aggressive treatment of Sino-US trade, it is necessary to stabilize the exchange rate in the short term, avoid the devaluation of RMB first, and do not give Trump the excuse to criticize the RMB exchange rate. At the same time, we should be prepared for the worst-case scenario and for the US to allow the exchange rate to float freely in the event of unilateral trade sanctions against China.

Fourth, we should not rush to respond to any Trump administration's trade sanctions against China. Instead, we should form a united front and unite the majority of countries that support globalization and the forces within the United States that oppose Trump's policy to make effective countermeasures.

If Biden wins:

As an organic president, Biden will deal with Sino-US economic and trade relations in a different way from Trump. This difference may be reflected in the following aspects: first of all, Biden will return to multilateralism, strive to repair the U.S. alliance damaged by Trump, unite with US allies to reform the WTO, and restructure global trade rules. This kind of trade rules may have strong pertinence to China. Biden is likely to discuss China's continued large-scale holdings of US treasury bonds to maintain the balance of the global financial system under the global dollar system.

What should we do?

First of all, we should firmly maintain the multilateral system. Maintaining the multilateral system is an endogenous requirement of the multi-polarization of the world economy. In today's world, especially in the post epidemic world, the economic volume and technological comparison between China and the United States will further change, and the total economic volume of developing and developed economies will also change. No matter how the United States reforms the WTO, China should actively participate in the WTO reform program, strive to retain the differential preferential terms in different stages of economic development in the WTO, and strive for the fairness and impartiality of the main WTO rules ${ }^{[6]}$.

Second, actively promote regional economic cooperation. The impact of the novel coronavirus pneumonia has caused the global industrial chain safety to be impacted. Besides self-innovation, it is necessary to improve the industrial chain and actively promote economic cooperation in the Asian region.

Third, China's technological innovation should be separated from the U.S. technological "hegemony". Under the background of US technology blockade, China is forced to strengthen its technological innovation to a certain extent. If the "neck sticking" technology is not solved, it will be difficult for China's economy to achieve high-quality growth, and the risks of high-tech industrial chain will be exposed. Once there is trade friction, the safety of the industrial chain will be endangered. But we must concentrate our efforts on developing high-tech industries.

Forth, we should combine the stable dollar system with the internationalization of RMB. The United States wants China to hold a large number of US treasury bonds, but the United States uses the US dollar system without restraint, and excessive currency issuance will inevitably cause the world to worry about US dollar assets. China can play an important role in balancing the global financial system. RMB internationalization is not to compete with the US dollar for the dominance of the international monetary system. RMB internationalization is the endogenous requirement of China's economic and financial development.

\section{Mathematical model analysis}


Firstly, cluster analysis is carried out on multiple factors of influencing factors, and then principal component analysis is carried out to select the factors with high correlation degree, and then the factors are weighted. We use different methods to analyze and plan the factors, and establish several more accurate and intuitive relations. The first problem we used is the method of analysis and planning. The second one continued the idea of the first question and got a good solution by referring to the formula we have derived. In the third question, we have collected the relevant information more extensively and have given the reasonable answer.

\section{Advantages and disadvantages}

We analyze many factors simply, effectively and comprehensively, and use reasonable function model and more accurate data and charts. The results given are very similar to those of the New York Times. However, our model lacks accuracy constraints on short-term data, and is not accurate in terms of accuracy. The parameter setting is not comprehensive, and the analysis method is relatively simple. Under the influence of the epidemic situation, the data we get is inaccurate and unstable, so it is difficult to make a perfect mathematical analysis model.

\section{References}

1. Tollefson J. Scientists relieved as Joe Biden wins tight US presidential election [Internet]. Nature 2020. Available from: https://www.nature.com/articles/d41586-020-03158-8.

2. Polymetal hopes for inclusion in GDM index after U.S. presidential election, reduction of geopolitical risks [Internet]. Interfax Group 2020. Available from: https://interfax.com/newsroom/top-stories/70104/.

3. Garand JC, Qi D, Magaña M. Perceptions of immigrant threat, American identity, and vote choice in the 2016 U.S. presidential election. Political Behavior 2020.

4. Wang H, Ge Y. Negotiating national identities in conflict situations: The discursive reproduction of the Sino-US trade war in China's news reports. Discourse \& Communication 2020; 14(1).

5. Qian X. China-US clean energy relation: Development, challenges, and forecast. US-China Law Review 2018; 15(4): 190 - 196.

6. Balaji AB, Rudd C, Liu X. Recycled carbon fibers (rCF) in automobiles: Towards circular economy. Materials Circular Economy 2020. 